\title{
The right ventricle in the systemic circulation: Why do some fail?
}

\author{
Charles D. Fraser, Jr, MD
}

\author{
From the Division of Congenital Heart Surgery, Texas Children's Hospital, Houston, Tex. \\ Disclosures: Author has nothing to disclose with regard to commercial support. \\ Received for publication July 11, 2017; accepted for publication July 14, 2017. \\ Address for reprints: Charles D. Fraser, Jr, MD, Texas Children's Hospital, Baylor College of Medicine, Congen- \\ ital Heart Surgery, 6621 Fannin St, West Tower, TCH 19th Floor, Houston, TX 77030 (E-mail: cdfraser@ \\ texaschildrens.org) \\ J Thorac Cardiovasc Surg 2017; 154:1733 \\ $0022-5223 / \$ 36.00$ \\ Copyright (C) 2017 by The American Association for Thoracic Surgery \\ http://dx.doi.org/10.1016/j.jtcvs.2017.07.030
}

In patients with congenital heart disease, the right ventricle (RV) is frequently associated with a workload seemingly beyond that which it is "designed" to sustain. Categories of increased RV afterload include the morphologically RV that is associated with the systemic circulation by anatomic derangement. This may be in the setting of atrioventricular discordance, such as in dextrotransposition of the great arteries (TGA) after an atrial switch procedure or in untreated congenitally corrected TGA (discordant transposition). It is well known in both dextro-TGA and congenitally corrected TGA that some RVs hold up very well under systemic workload, while others do not. Why? Similarly, surgical palliation for hypoplastic left heart syndrome requires that the single RV be able to sustain a systemic workload. Unfortunately, RV dysfunction remains a leading cause of morbidity and mortality in palliated hypoplastic left heart syndrome. Some RVs simply cannot manage the workload. Why? More commonly, patients with surgically repaired tetralogy of Fallot, double-outlet RV, and pulmonary atresia with ventricular septal defect face a lifelong risk of progressive RV compromise, particularly in the setting of pulmonary hypertension (most typically related to pulmonary artery architecture concerns). Some of these patients do quite well in the long term, while other RVs are not able to hold up. Why?

These are just some examples to emphasize how little we truly know about the best methods to coax the RV into doing more work or how to decide which RVs cannot sustain the systemic circulation. The ramifications are critical, and it seems that the field of congenital heart surgery is rather limited by our inability to determine precisely which RVs

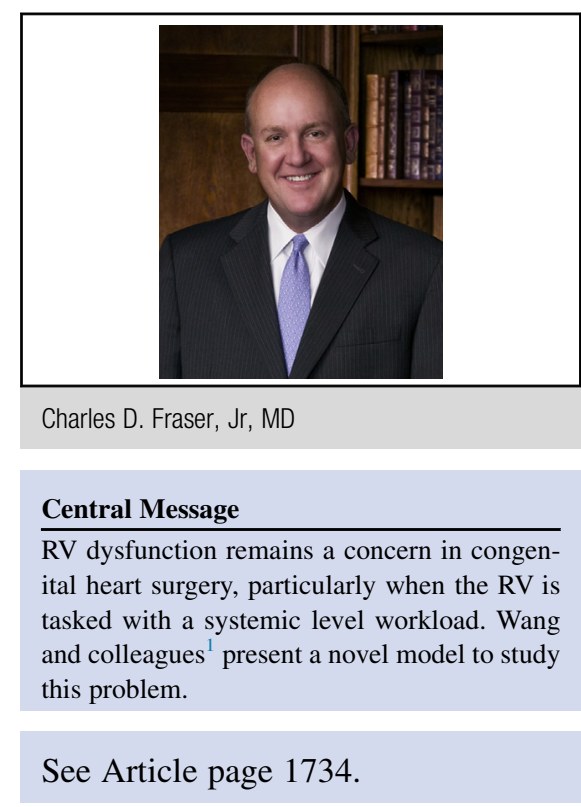

will perform optimally in a setting of increased afterload. As such, I find the article by Wang and colleagues ${ }^{1}$ in this issue of the Journal fascinating and with considerable potential to help us further our understanding of the effects of increased afterload on RV performance. The model that Wang and colleagues ${ }^{1}$ have successfully developed is amazing in and of itself. Achieving effective pulmonary artery banding in neonatal rats as they have done represents, to my view, quite an accomplishment. With this achievement, Wang and colleagues ${ }^{1}$ have added significantly to the research opportunities, which may further our understanding of how the developing RV may accommodate to increased afterload. The potential is enormous and important. I look forward to seeing the model refined further and clinical important hypotheses developed and tested.

\section{Reference}

1. Wang S, Ye L, Hong H, Tang T, Li M, Zhang Z, et al. A neonatal rat model of increased right ventricular afterload by pulmonary artery banding. J Thorac Cardiovasc Surg. 2017;154:1734-9. 